\title{
Underwater endoscopic papillectomy using double-balloon endoscopy
}

A 70-year-old woman with familial adenomatous polyposis (FAP), who had undergone proctocolectomy for FAP and laparoscopic total gastrectomy with Roux-en-Y reconstruction for multiple early gastric cancers, underwent doubleballoon endoscopy (DBE) for duodenal adenoma screening. DBE revealed an ampullary tumor, diagnosed as a tubular adenoma by biopsy ( $\mathbf{F i g} \mathbf{1}$ a). For resection of the ampullary tumor, we planned an underwater endoscopic papillectomy. We used a short-type double-balloon endoscope (El-580BT; Fujifilm, Tokyo, Japan), equipped with an auxiliary waterjet injection cap (Water Please AF-WP1; Forte Grow Medical Co. Ltd., Tochigi, Japan) to allow irrigation while leaving the operative channel free. We performed underwater papillectomy using a singleuse snare (Captivator II; Boston Scientific, Tokyo, Japan) without submucosal injection ( $\triangleright$ Fig.1 b,c). A 5-Fr plastic stent (Geenen pancreatic stent; Cook Medical, Tokyo, Japan) was placed into the main pancreatic duct to prevent post-papillectomy pancreatitis and the mucosal defect was closed with clips (QuickClip Pro; Olympus, Tokyo, Japan) ( $\triangleright$ Fig. 1 d).

The patient did not experience any early adverse events and was discharged on postoperative day 7. The pathological diagnosis of the resected tumor confirmed it to be a tubular adenoma and the resection margins were free of dysplasia.

Endoscopic papillectomy (EP) is a less invasive treatment for localized ampullary tumors; however, the procedure is not standardized, and severe adverse events such as pancreatitis, perforation, bleeding, and cholangitis may occur after the procedure [1,2]. Underwater endoscopic mucosal resection (EMR) has been reported as a novel approach for the treatment of small duodenal adenomas $(\leq 20 \mathrm{~mm})$ [3], but the efficacy of the procedure and its safety for ampullary tumors are unclear. In this case, we applied the underwater EMR technique to an en-

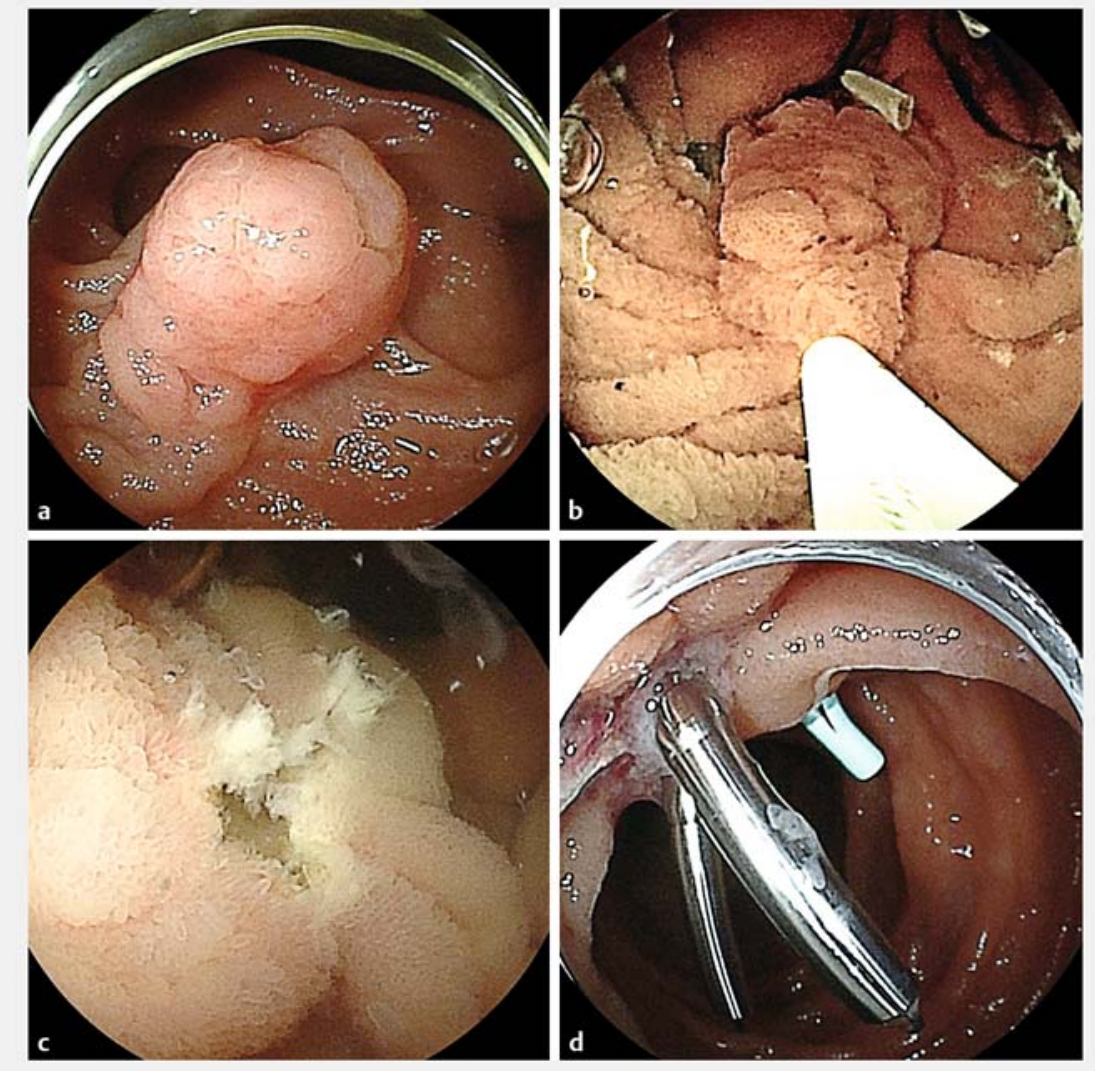

Fig. 1 Endoscopic images showing: $\mathbf{a}$ an adenoma of the papilla of Vater; $\mathbf{b}$ the ensnared papilla during underwater papillectomy (underwater view); c the appearance following underwater papillectomy (underwater view); $\mathbf{d}$ insertion of a pancreatic stent into the main pancreatic duct (MPD) and closure of the mucosal defect with clips.

doscopic papillectomy procedure using DBE. The underwater EMR technique has been similarly reported to be a safe and novel treatment approach for an ampullary tumor in a patient with altered gastrointestinal anatomy [4].

Endoscopy_UCTN_Code_TTT_1AR_2AF

\section{Competing interests}

None
The authors

Tatsuhiro Yamazaki, Daisuke Uchida, Yasushi Yamasaki, Takeshi Tomoda, Kazuyuki Matsumoto, Hironari Kato, Hiroyuki Okada Department of Gastroenterology, Okayama University Hospital, Okayama, Japan

\section{Corresponding author}

Tatsuhiro Yamazaki, MD

Department of Gastroenterology, Okayama University Hospital, 2-5-1 Shikata-cho, Okayama 700-8558, Japan

Fax: +81-86-2255991

ty1114db@gmail.com 


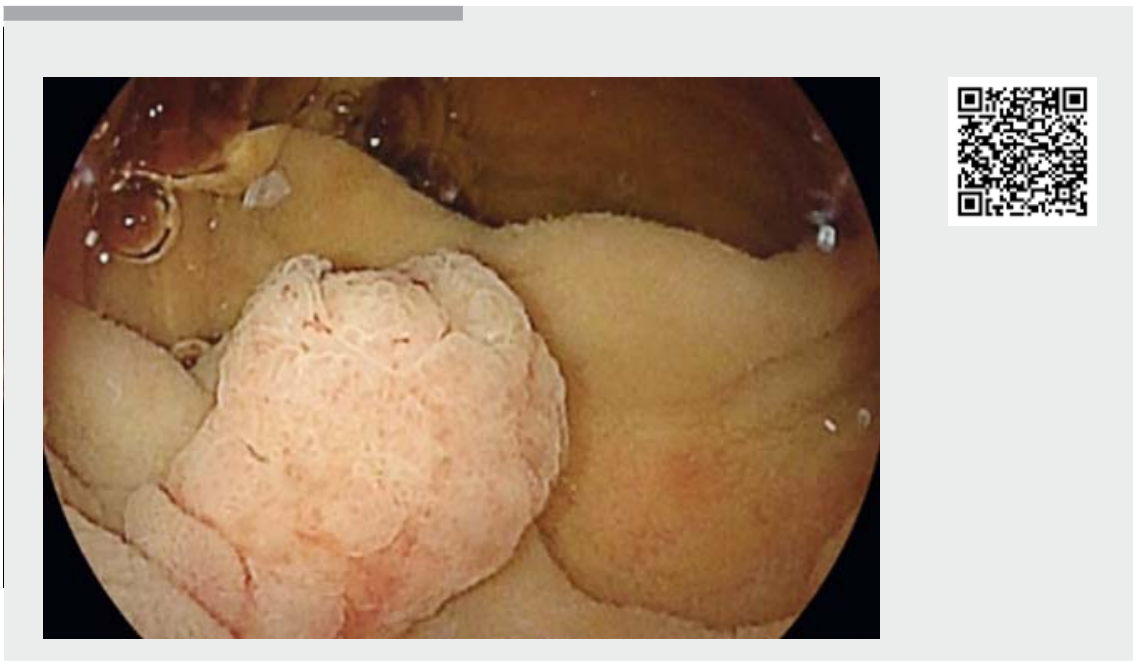

Video 1 Underwater endoscopic papillectomy of an adenoma of the papilla of Vater.

\section{References}

[1] Kang SH, Kim KH, Kim TN et al. Therapeutic outcomes of endoscopic papillectomy for ampullary neoplasms: retrospective analysis of a multicenter study. BMC Gastroenterol 2017; 17: 69

[2] Tsuji S, Itoi T, Sofuni A et al. Tips and tricks in endoscopic papillectomy of ampullary tumors: single-center experience with large case series (with videos). J Hepatobiliary Pancreat Sci 2015; 22: E22 - E27

[3] Yamasaki Y, Uedo N, Takeuchi Y et al. Underwater endoscopic mucosal resection for superficial nonampullary duodenal adenomas. Endoscopy 2018; 50: $154-158$

[4] Granata A, Curcio G, Ligresti D et al. Endoscopic ampullectomy: to inject or not to inject? The underwater technique Endoscopy 2014; 46 (Suppl. 01): E478-E479

\section{Bibliography}

DOI https://doi.org/10.1055/a-0992-9084

Published online: 9.9.2019

Endoscopy 2020; 52: E55-E56

(c) Georg Thieme Verlag KG

Stuttgart · New York

ISSN 0013-726X

\section{ENDOSCOPY E-VIDEOS}

https://eref.thieme.de/e-videos

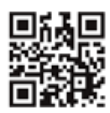

Endoscopy E-Videos is a free access online section, reporting on interesting cases and new

techniques in gastroenterological endoscopy. All papers include a high quality video and all contributions are freely accessible online.

This section has its own submission website at https://mc.manuscriptcentral.com/e-videos 